\title{
The Interaction Effects of Montmorillonite and Glycerol on the Properties of Polyvinyl Alcohol-montmorillonite Films
}

\author{
Akbar Jokar ${ }^{1}$, Mohamad Hossein Azizi $^{2}$, Zohre Hamidi Esfehani ${ }^{2}$ \\ 1- Assistant prof, Agriculture Engineering Research Department, Fars Agricultural and Natural Resources Research and Education Center, Zarghan, \\ Shiraz, Iran. \\ 2- Dept.of Food Science, College of Agriculture, Tarbiat Modares University, Tehran, Iran.
}

Accepted: February 2017

\section{A B S T R A C T}

Background and Objectives: Preparation and evaluation of nanocomposite films have become prevalent in recent years. Depending on the purpose of using the film, and considering the effects and interaction effects of nanomaterial and other modifiers on the film properties, the amounts of nanomaterials and modifiers should be optimized. The effects of montmorillonite (MMT), glycerol (GL), and their interaction effects on the properties of polyvinyl alcohol-montmorillonite (PVA-MMT) films were evaluated in this research.

Materials and Methods: PVA-MMT films were produced based on a full factorial experiment in a completely randomized design (CRD) with 16 treatments and three replicates. There were two factors with four levels: MMT $(0,5,12$, and $20 \%$ weight per weight of polymer W/WP), and GL $(0,10,30$, and 50\% W/WP). The films were characterized by mechanical properties, opacity, water vapor permeability $(W V P)$, and color.

Results: MMT increased tensile strength $(T S), b^{*}$, yellowness index $(Y I)$, and opacity of the films. MMT, however, reduced elongation (E\%) and $W V P$ of the films. The effect of GL on the films was quite opposite the MMT. In addition, the interaction effects of MMT-GL on $W V P, Y I$, and $b^{*}$ were significant $(\mathrm{p}<0.01)$. MMT contents could reduce $W V P$ just in the presence of GL in the films, while GL contents could increase $W V P$ at all MMT concentrations. Furthermore, MMT contents could increase $Y I$ of the films at all GL concentrations, while GL could increase YI just at 20\% MMT content. Strong affinities of MMT, and GL with PVA were proved by FTIR.

Conclusions: Considering the target of utilizing PVA-MMT films, appropriate concentrations of MMT, GL, and their proper combination should be selected.

Keywords: Polyvinyl alcohol, Composite film, Montmorillonite, Glycerol, Interaction effects, FTIR

\section{Introduction}

Since 1970, the production and utilization of plastics in the world have considerably increased. Problems of waste disposal have motivated studies toward the development of polymers that could be degraded more rapidly in the environment (i.e., mineralization or bioassimilation). Designing, synthesizing and utilizing biodegradable polymers, especially natural ones offer a possible alternative to these non-biodegradable materials, particularly when their collection and processing are not possible and economical $(1,2)$. The most important barriers in using biodegradable natural materials, particularly for packaging are their poor mechanical, thermal, and moisture resistance properties. In recent years, nanocomposites such as polymer-layered silicate have become prevalent. Silicate layers should possess at least one dimension of less than $100 \mathrm{~nm}$ (3-5). MMT is a type of silicate clay that has been widely utilized in polymer nanocomposites. High intercalation chemistry, strength, abundance in nature, low gas permeability, safety, and economic properties of 
MMT have resulted to the prevalent use of this material (6-9).

PVA is a safe and synthetic polymer, widely utilized in industrial, commercial, medical and food applications (10). There are several developments in PVA-based nanocomposite films and its blend with starch and other biodegradable polymers. In addition to user friendly characteristics like low cost and approximate high biodegradation rate, PVA can be used in food packaging as it demonstrates a broad and universal range of suitable technological properties $(11,12)$.

Several investigations have revealed that incorporating nano-scaled silicate layers into polymers like PVA increases their mechanical properties, heat, and moisture/oxygen resistance, and reduces their moisture/oxygen adsorption, permeability, and flammability $(11,13,14)$.

The addition of MMT to PVA or other polymers usually increases their hardness, which is a property that should be modified in order to meet the requirements for appropriate applications. GL is one of the most popular plasticizers for this purpose. Some researchers have utilized GL as a plasticizer in PVA, particularly in starch-PVA films. Mao et al. (2000) reported that GL enhanced the elongation of extruded starch films, while PVA improved both $E \%$ and TS of starch-GL (15). Lin and Tung (2010) stated that GL had an excellent plasticizing effect on starch and PVA films, and improved their thermoplastic properties (16). Salleh et al. (2012) examined the effect of GL content on modified polyvinyl alcoholtapioca starch. They found that adding GL enhanced the flowability during the extrusion processing, and concluded that the quantity of GL must be optimized to ensure that the mechanical properties of the blends are not negatively affected. To the best of the authors' knowledge, there are no reports that reveal and discuss the interaction effects of MMT-GL on popular films like PVA.

The present study was designed to demonstrate the importance of the interaction effects of MMT-GL and their optimization in order to obtain a PVA-MMT film with desired properties.

\section{Materials and Methods}

Materials: PVA was purchased from LOBA Chemie, Mumbai, India (Polymerization degree: 1700-1800, Viscosity of its 2\% solution: 25-32 cp, Hydrolysis: 98-99\% mole). MMT without any modifications was procured from Southern Clay Products Inc., USA (Cloisite $\mathrm{Na}+$ ), and GL (Pub Chem CID: 753) was obtained from the Merck Company, Germany.

MMT characterizations: Particle size distribution of MMT suspensions was assessed via Malvern Zetasizer Nanoseries Nano-ZS (UK). Samples of MMT suspension were collected just before they were added to the polymer solution (Fig. 1) and then diluted to proper concentration for analysis by Zetasizer. The XRD measurement (X'PertMPD, Philips, Holland XRD) revealed the initial d-space between the silicate layers.

MMT preparation: The MMT preparation is illustrated in Fig. 1. All of the MMT preparations were performed in $100 \mathrm{ml}$ laboratory beakers. Stirrers and magnet stirring sets were of Heidolf MR 3001 (Germany) and $2 \mathrm{~cm}$ magnet, respectively. In the MMT preparations, a water bath sonicator was utilized (ULTRASONS-H, PSelecta CE95, $50 \mathrm{kHz}$, $1000 \mathrm{~W})$. At all stages of MMT preparation, the top of the beakers was tightly wrapped with a soft polyethylene sheet to prevent water vaporization.

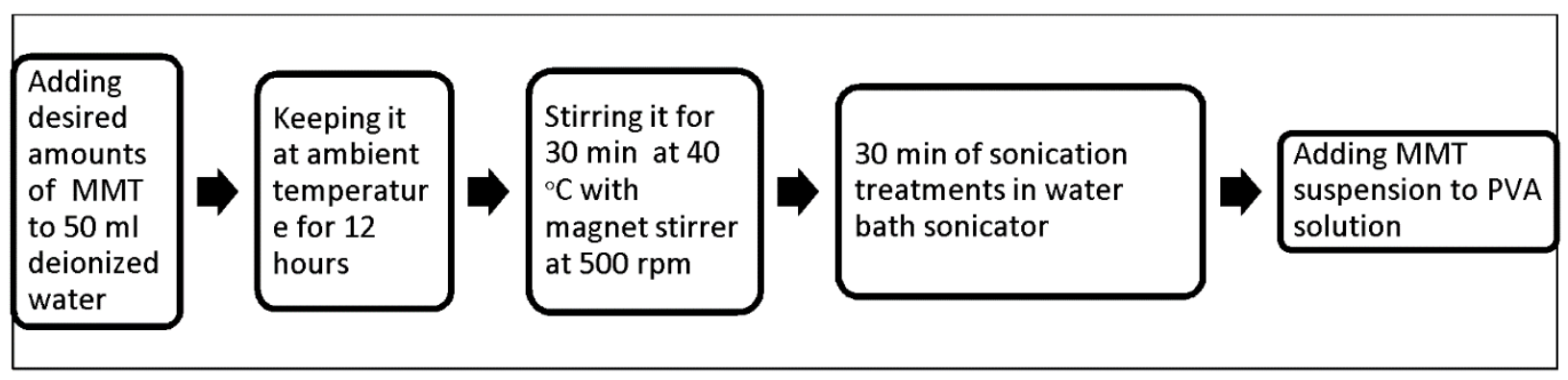

Figure 1. MMT preparation. 
Film preparation: Each polymer possesses individual characteristics, and the method of film preparation is exclusive. The process of film preparation is shown in Fig. 2. In PVA-MMT film preparation, stirrer and magnet stirring were of Heidolf MR 3001 and $6 \mathrm{~cm}$ magnet, respectively. A water bath sonicator (ULTRASONS-H, PSelecta CE95, $50 \mathrm{kHz}, 1000 \mathrm{~W}$ ) was utilized in the film preparation. From the start to the end of film preparation, $500 \mathrm{ml}$ blue cap glass containers were utilized and tightly wrapped to prevent the solvent evaporation.

Properties of PVA-MMT films: PVA-MMT films were characterized by mechanical properties (TS and $E \%$ ), opacity, $W V P$, color, $Y I$, and thickness. XRD was utilized to examine the dispersion of MMT in the PVA polymer. FTIR spectroscopy was employed to reveal the changes and emergence of chemical bonds as a result of the incorporation of MMT and GL to PVA.

Mechanical properties: TS (a measurement of the force needed to pull an object such as rope, wire, or a structural beam to the point where it breaks) and E\% (measure of the ductility of a material as determined by a tension test; it is the increase in the gauge-length of a test specimen after the fracture is divided by its original gauge-length). Evaluations were carried out using a texture analyzer (Instron, Hounsfield H50KS, England) based on the standard of ASTM D882-12 (17). The speed of upper Instron's jaw was 50 $\mathrm{mm} / \mathrm{min}$. Rectangular strips $(8 \times 1 \mathrm{~cm})$ were cut from the film sheets. In addition, using adhesive paper scotch, $2 \mathrm{~cm}$ from the top and bottom of the strips was carefully wrapped to prevent compression, rupture, and slipping of the films between the Instron's jaws. The distance between the jaws was $4 \mathrm{~cm}$. The strips were equilibrated at $25^{\circ} \mathrm{C}$ and $50 \% \mathrm{RH}$ for $72 \mathrm{~h}$ before conducting the test.

X-ray diffraction (XRD): Exfoliate and the intercalate structures of PVA-MMT films were evaluated using X'PertMPD, Philips, Holland XRD diffractometer equipped with $\mathrm{CO} \mathrm{K \alpha} \quad 1.79^{\circ} \mathrm{A}$ (scanning rate of $0.02^{\circ} / \mathrm{s}$, scan step time of $2 \mathrm{~s}$, voltage of $40 \mathrm{kV}$, and current of $30 \mathrm{~mA}$ ). Data collection was carried out at $2 \theta$ angle from 1 to $12^{\circ}$. The most suitable and popular method for calculating the dspace of MMT in such films and proving the penetration of polymer into the MMT layers (Intercalate structure) is employing Bragg equation. Disappearing of MMT peak in the XRD spectra of the films reveals exfoliate structure $(18,19)$.

The XRD software calculated the d-space of MMT layers according to Bragg equation (18):

$\lambda=2 \mathrm{~d} \sin \theta \quad$ (Eq. 1)

Where, $\lambda$ is the wavelength of the X-ray beam (nm), $d$ is the space (nm) between the two layers, and $\theta$ is the angle of incidence.

Fourier transform infrared spectroscopy (FTIR): FTIR spectra were collected using FTIR spectrometer (Nexus 6700, Thermo Nicolet, USA). The transmission method was applied to the films. IR absorption spectra of the films were obtained for the purposes of measuring and scanning. The spectral collections were carried out in the wavenumber range of $400-4000 \mathrm{~cm}^{-1}$ with the resolution of $4 \mathrm{~cm}^{-1}$.

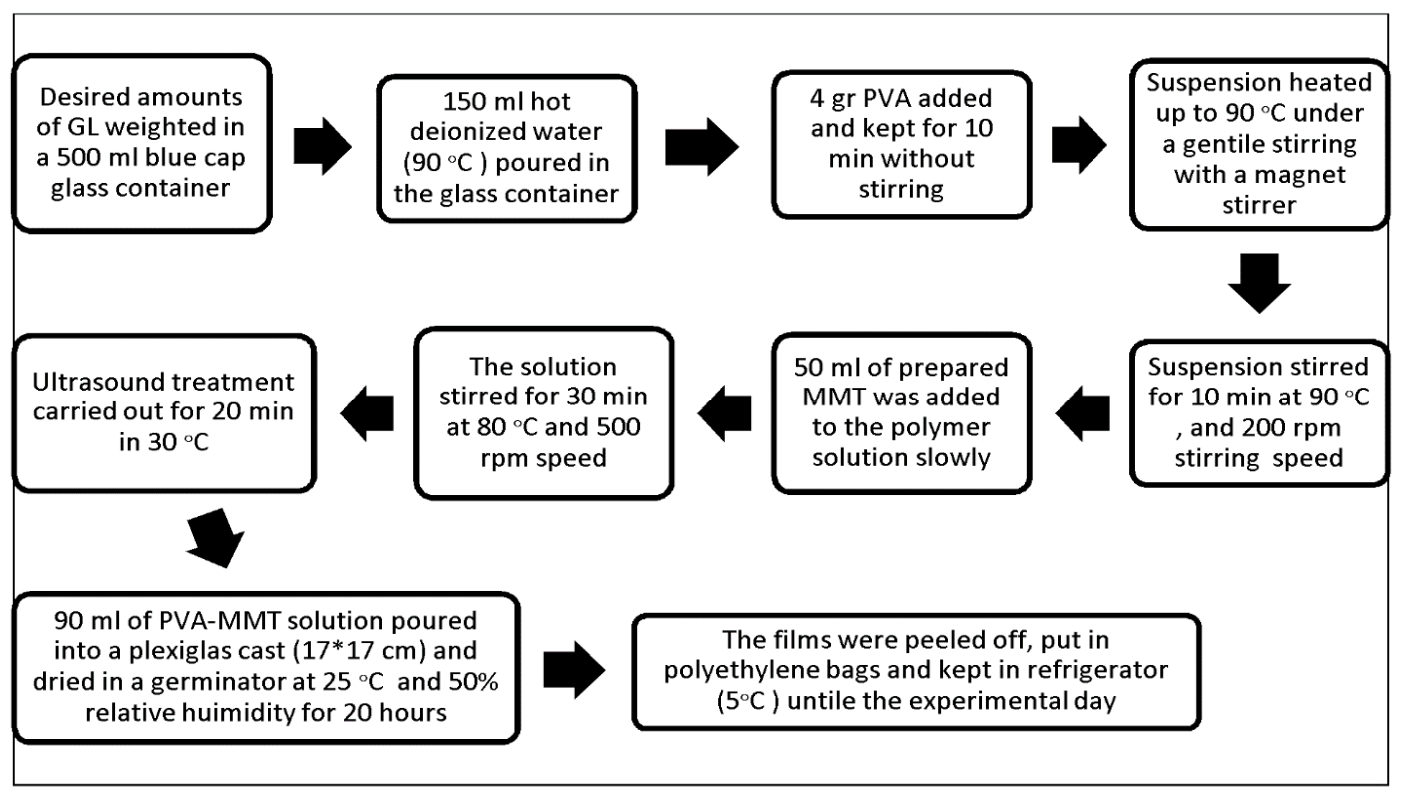

Figure 2. Preparation of PVA-MMT films. 
Opacity: The opacity (the degree to which light is not allowed to travel through) of the films was measured using a Cary $60 \mathrm{UV} / \mathrm{Vis}$ spectrophotometer (USA). Rectangular pieces of the films were prepared, and put in the sample position of the spectrophotometer utilizing the empty measurement as the reference. The opacity of the films was calculated as below $(8,20$, 21):

Opacity $=\frac{\mathrm{Abs} 600}{\mathrm{X}} \quad$ (Eq. 2)

Where, Abs600 is the absorbance at $600 \mathrm{~nm}$, and $X$ is the thickness $(\mathrm{mm})$ of the films.

Water Vapor Permeability (WVP): The WVP evaluations were based on the modified ASTM E96/E96 M-14 method (22). Before running the test, the circle samples $\left(19.625 \times 10^{-4} \mathrm{~m}^{2}\right.$ in the surface area) were cut and equilibrated at $25^{\circ} \mathrm{C}$ and $50 \% \mathrm{RH}$ for $72 \mathrm{~h}$. Then they were carefully placed and sealed utilizing grease oil on the top of the glass cells $\left(7.065 \times 10^{-4} \mathrm{~m}^{2}\right.$ in the internal surface area, $19.625 \times 10^{-4} \mathrm{~m}^{2}$ in the edge surface area, and the depth of $3.5 \mathrm{~cm}$ ), which contained $8 \mathrm{ml}$ saturated $\mathrm{NaCl}$ (74\% RH). To avoid the leakage of moisture through the seals, in addition to using grease oil, circle rubber rings were placed on the films as well as on the edges of the cells, and tightly gripped by four metal clamps. The glass cells were placed in a desiccator containing $800 \mathrm{~g}$ silica gel at $25^{\circ} \mathrm{C}$ and $50 \% \mathrm{RH}$. The cells were weighed every $5 \mathrm{~h}$ for $72 \mathrm{~h}$. WVP was calculated as follows:

$W V P=\frac{\Delta \mathrm{m} \times \mathrm{X}}{\mathrm{A} \times \Delta \mathrm{t} \times \Delta \mathrm{p}} \quad$ (Eq. 3)

Where, WVP is water vapor permeability $(\mathrm{g} / \mathrm{m} . \mathrm{hr} . \mathrm{kPa}), \Delta \mathrm{m}$ is is the total weight loss of the cells (g), $X$ is the thickness of the films (m), $A$ is the internal or exposed area of the film $\left(\mathrm{m}^{2}\right), \Delta \mathrm{t}$ is the time of vapor penetration (h), and $\Delta p$ is pressure gradient $(\Delta p=2.368 \mathrm{kPa}$ was calculated using a psychrometric chart from Universal Industrial Gases, Inc, Pennsylvania, USA).

\section{Appearance evaluations}

Color: $L^{*}, a^{*}$ and $b^{*}$ parameters (CIE modes) of the films were measured in a tristimulus colorimeter (ColorFlex EZ, Bench top Spectrophotometers, USA). Five replicates were performed for each sample (20).

Yellowness Index (YI): The YI of the films was measured based on the standard of ASTM E313-15 (23). Eq. 4 was utilized for $Y I$ calculation:

$Y I=\frac{(\mathrm{Cx} . \mathrm{X}-\mathrm{Cz} . \mathrm{Z})}{\mathrm{Y}} \times 100$ (Eq. 4)
Where, $X, Y$ and $Z$ are tristimiulus factors measured by a tristimulus colorimeter (ColorFlex EZ, Benchtop Spectrophotometers, USA). $C x$, and $C z$ are constants obtained from the ASTM E313-15 standard.

Thickness: Using a micrometer (Mitutoyo, Model0052526, Japan), the thickness of the PVAMMT films was measured. Five locations of the films were evaluated, and the average value was utilized for each sample.

Statistical design: PVA-MMT films were produced based on a full factorial experiment in a completely randomized design (CRD). There were two factors with four levels: MMT $(0,5,12$, and $20 \%$ weight per weight of polymer W/WP) and GL $(0,10,30$, and $50 \%$ W/WP). Therefore, 16 treatments were obtained (Table 1). Data were analyzed mainly with the SPSS software (ver. 20). Design Expert (ver. 7.0) was utilized for optimization. Using numerical optimization, goals for each response were set, and the software generated optimal conditions. When there was an interaction effect between the factors, SAS (ver. 9.0) was utilized for analyzing the effects of MMT concentrations at each concentration of GL, and vice versa. Duncan's multiple range test was conducted for mean comparisons $(\alpha=0.05)$. All experiments and measurements were performed with at least three replicates.

Table 1. PVA-MMTexperimental full factorial treatments

\begin{tabular}{l}
\hline PVA Treatments \\
\hline 0 MMT 0 GL \\
5 MMT 0 GL \\
12 MMT 0 GL \\
20 MMT 0 GL \\
0 MMT 10 GL \\
5 MMT 10 GL \\
12 MMT 10 GL \\
20 MMT 10 GL \\
0 MMT 30 GL \\
5 MMT 30 GL \\
12 MMT 30 GL \\
20 MMT 30 GL \\
0 MMT 50 GL \\
5 MMT 50 GL \\
12 MMT 50 GL \\
20 MMT 50 GL \\
\hline
\end{tabular}

Results

MMT characterization: MMT characteristics (Company datasheet, ZetaSizer results, and XRD results) are shown in Table 2. 
Table 2. MMT characteristics

\begin{tabular}{|c|c|c|c|c|c|c|c|c|}
\hline \multicolumn{5}{|c|}{ Southern Clay Company datasheet $\left(\right.$ Cloisite $\left.\mathrm{Na}^{+}\right)$} & \multicolumn{3}{|c|}{ Zetasizer (0.4\% suspension) } & XRD \\
\hline d-space & $\begin{array}{c}\text { MMT } \\
\text { thickness }\end{array}$ & $\begin{array}{l}\text { Particle } \\
\text { size }\end{array}$ & $\begin{array}{l}\text { Specific } \\
\text { weight }\end{array}$ & $\begin{array}{l}\text { Bulk } \\
\text { density }\end{array}$ & $\begin{array}{c}\text { Zeta } \\
\text { potentioal }\end{array}$ & $\begin{array}{c}\text { Particle size } \\
\text { average }\end{array}$ & $\begin{array}{l}\text { Polydispersity } \\
\text { Index (PDI) }\end{array}$ & d-space \\
\hline $1.17 \mathrm{~nm}$ & $<50 \mathrm{~nm}$ & $<2 \mu \mathrm{m}$ & $2.86 \mathrm{~g} / \mathrm{ml}$ & $568 \mathrm{~g} / \mathrm{L}$ & -30.4 & $195 \mathrm{~nm}$ & 0.264 & $1.178 \mathrm{~nm}$ \\
\hline
\end{tabular}

Mechanical properties: The interaction effects of MMT-GL on $T S$ and $E \%$ were insignificant (p>0.05). As shown in Fig. 3 the effect of MMT and GL should be investigated individually.
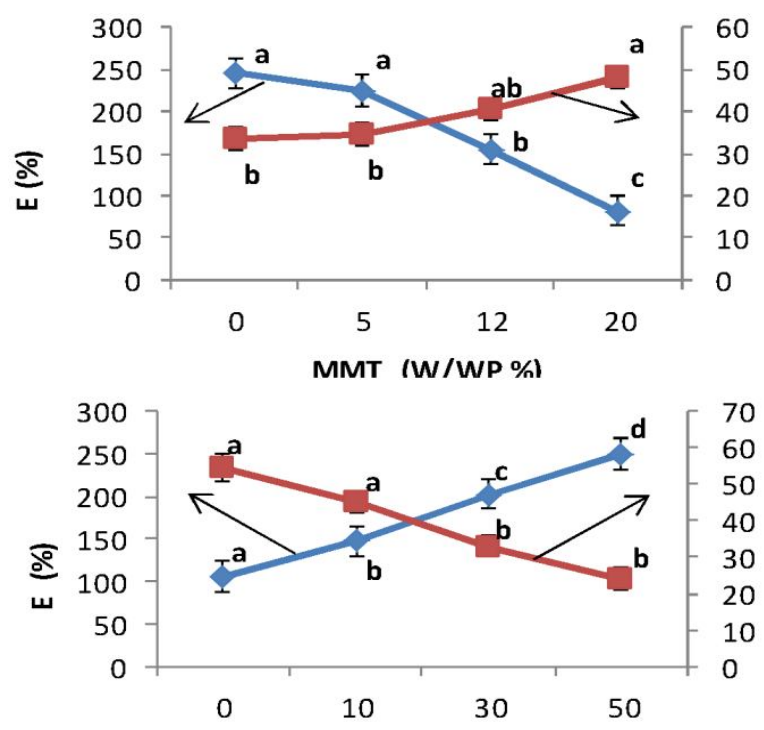

GL (W/WP \%)

Figure 3. The effects of GL and MMT contents on the TS and $E \%$ of PVA-MMT films.

Water Vapor Permeability $(\boldsymbol{W V} \boldsymbol{V})$ : The interaction effects of MMT-GL on WVP were significant $(\mathrm{p}<0.01)$. As illustrated in Table 3, the effect of MMT contents on $W V P$ was not significant at the GL of $0 \%$, while it was significant at all the other GL contents. The effect of GL contents on WVP was significant at all MMT contents (Table 4).

Table 3. The effects of MMT contents on $W V P$ at different GL concentrations

\begin{tabular}{cccccc}
\hline GL & df & SS & MSS & F & P \\
\hline 0 & 3 & 0.008 & 0.003 & 0.51 & 0.68 \\
10 & 3 & 0.115 & 0.038 & 7.11 & 0.001 \\
30 & 3 & 0.232 & 0.077 & 14.38 & 0.001 \\
50 & 3 & 0.106 & 0.038 & 6.56 & 0.001 \\
\hline
\end{tabular}

Table 4. The effects of GL contents on WVP at different MMT concentrations

\begin{tabular}{cccccc}
\hline MMT & df & SS & MSS & F & P \\
\hline 0 & 3 & 1.009 & 0.336 & 62.58 & 0.0001 \\
5 & 3 & 0.726 & 0.242 & 45.05 & 0.0001 \\
12 & 3 & 1.144 & 0.381 & 71.01 & 0.0001 \\
20 & 3 & 0.610 & 0.203 & 37.87 & 0.0001 \\
\hline
\end{tabular}

Fig. 4 illustrates the interaction effects of MMTGL, the effects of MMT and GL individually, and the higher effect of GL on WVP compared with MMT.

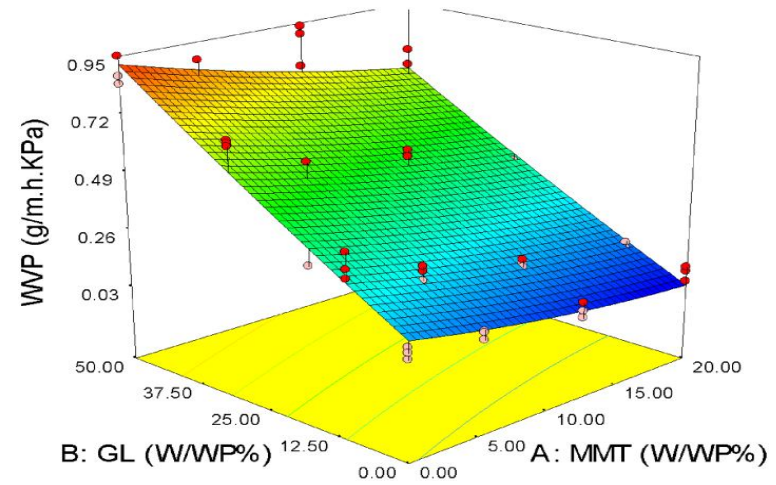

Figure 4. The interaction effects of MMT-GL on WVP of PVA-MMT films

Thickness: The effect of MMT and the interaction effect of MMT-GL on the thickness of the films were not significant ( $>>0.05)$, while the effect of GL was significant $(p<0.01)$. As illustrated in Fig. 5, the thickness of the films increased with increase in the GL contents.

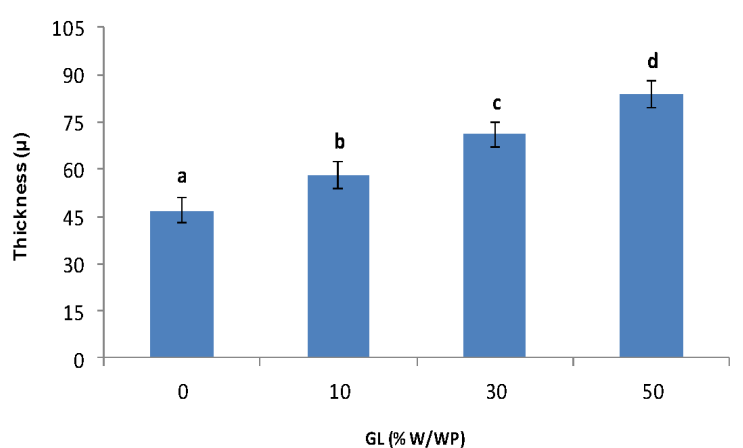

Figure 5. The effect of GL contents on the thickness of PVA-MMT films 
Appearance of PVA-MMT films: Data analysis revealed that the effect of MMT and interaction effect of MMT-GL on $b^{*}$ and $Y I$ were significant $(\mathrm{p}<0.01)$. The effects of MMT contents on $b^{*}$ and $Y I$ were significant at all GL concentrations $(\mathrm{p}<0.01)$, while the effect of GL was significant just at the $20 \% \mathrm{MT}$ content $(\mathrm{p}<0.01)$. Fig. 6 illustrates these effects.

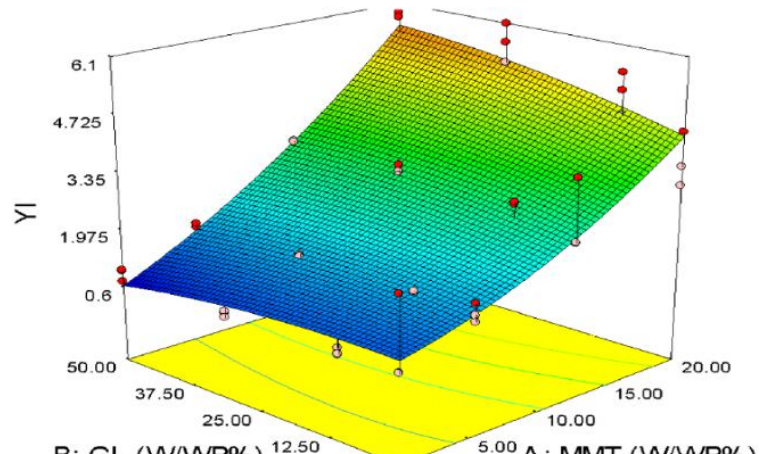

B: GL (W/WP\%) ${ }^{12.50} 0.000 .00{ }^{5.00} \mathrm{~A}:$ MMT (W/WP\%)

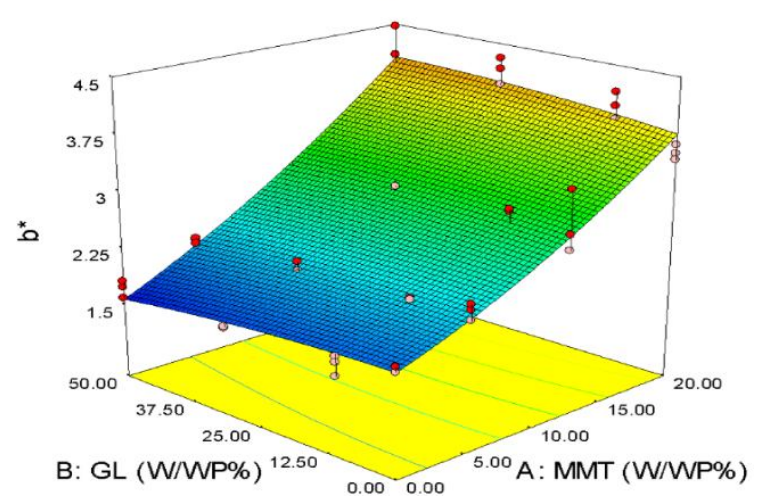

Figure 6. The interaction effects of MMT-GL on the $Y I$ and $b^{*}$ of PVA-MMT films

The effect of MMT contents on the opacity of the films was significant $(p<0.01)$. Fig. 7 reveals that increasing of the MMT contents increases the opacity of the films.

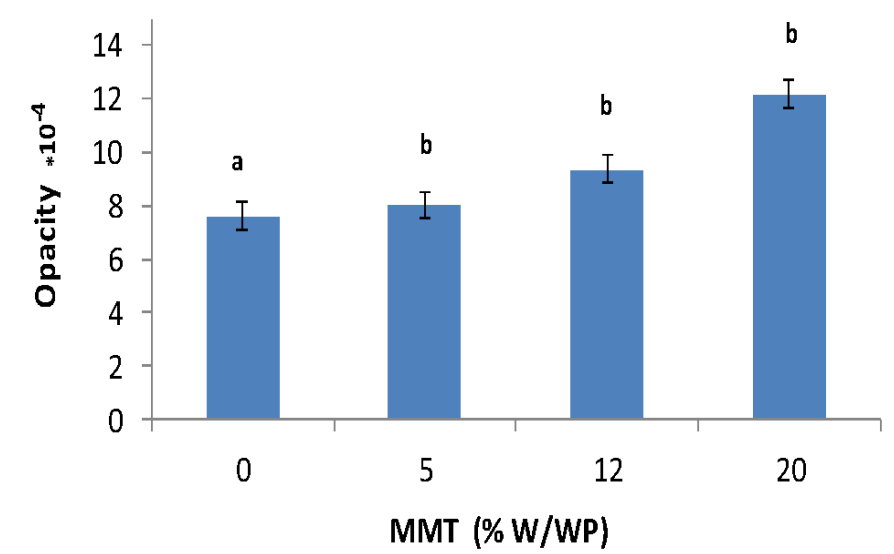

Figure 7. The effect of MMT contents on the opacity of PVA-MMT films

Optimization: Depending on the purpose of using the film and considering the effects of MMT and GL, the optimization of the film properties should be carried out. We intended to produce a MMT-GL film with the minimum WVP, opacity, and $200 \% E$, and optimization by using Design Expert software, which introduced a 5\%MMT-10\%GL treatment with $90 \%$ desirability.

Fourier transform infrared spectroscopy (FTIR): The FTIR spectra of PVA, MMT, GL, and PVAMMT films are illustrated in Fig. 8.

X-ray diffraction (XRD): Fig. 9 illustrates the XRD graphs of pure MMT and PVA-MMT films. The effects of increasing the MMT contents on the dispersion of MMT in the PVA matrix are shown in Fig. 9.

Table 5 shows d-space and angles of the XRD peaks.

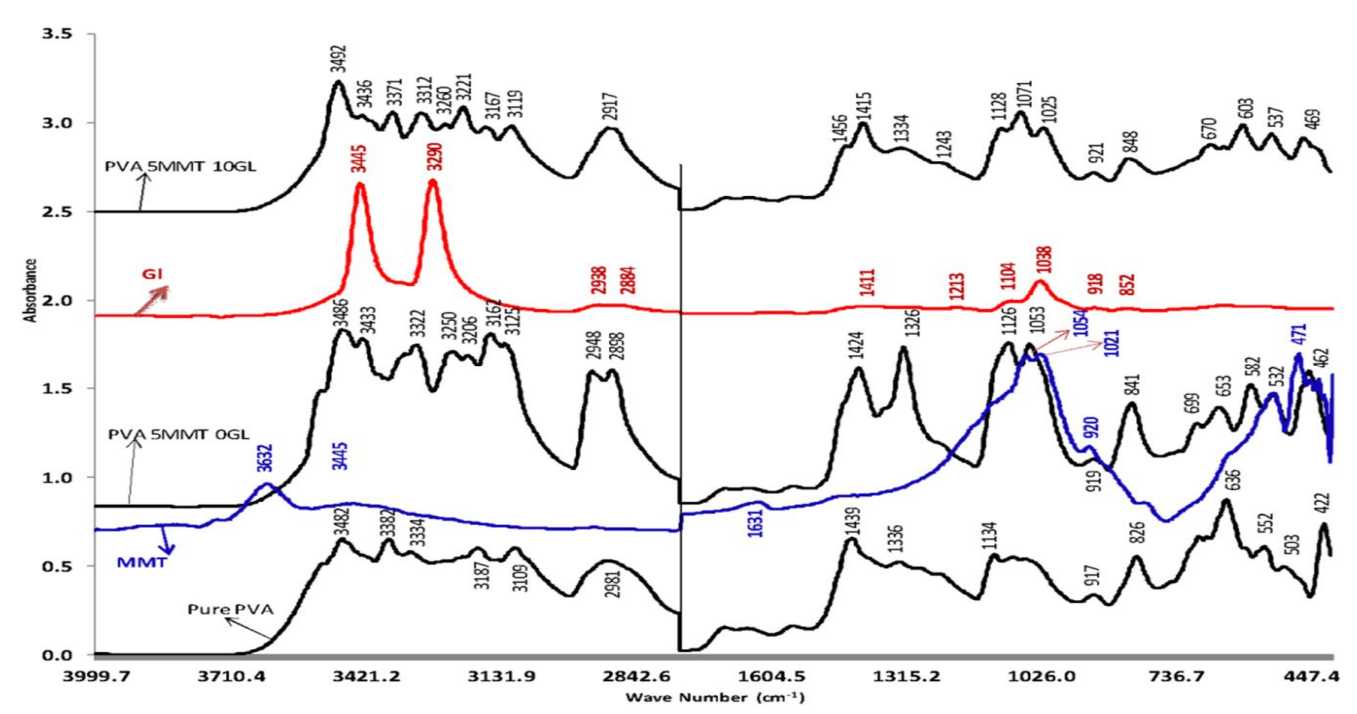

Figure 8. FTIR spectrum of PVA, MMT, GL, and PVA-MMT films 


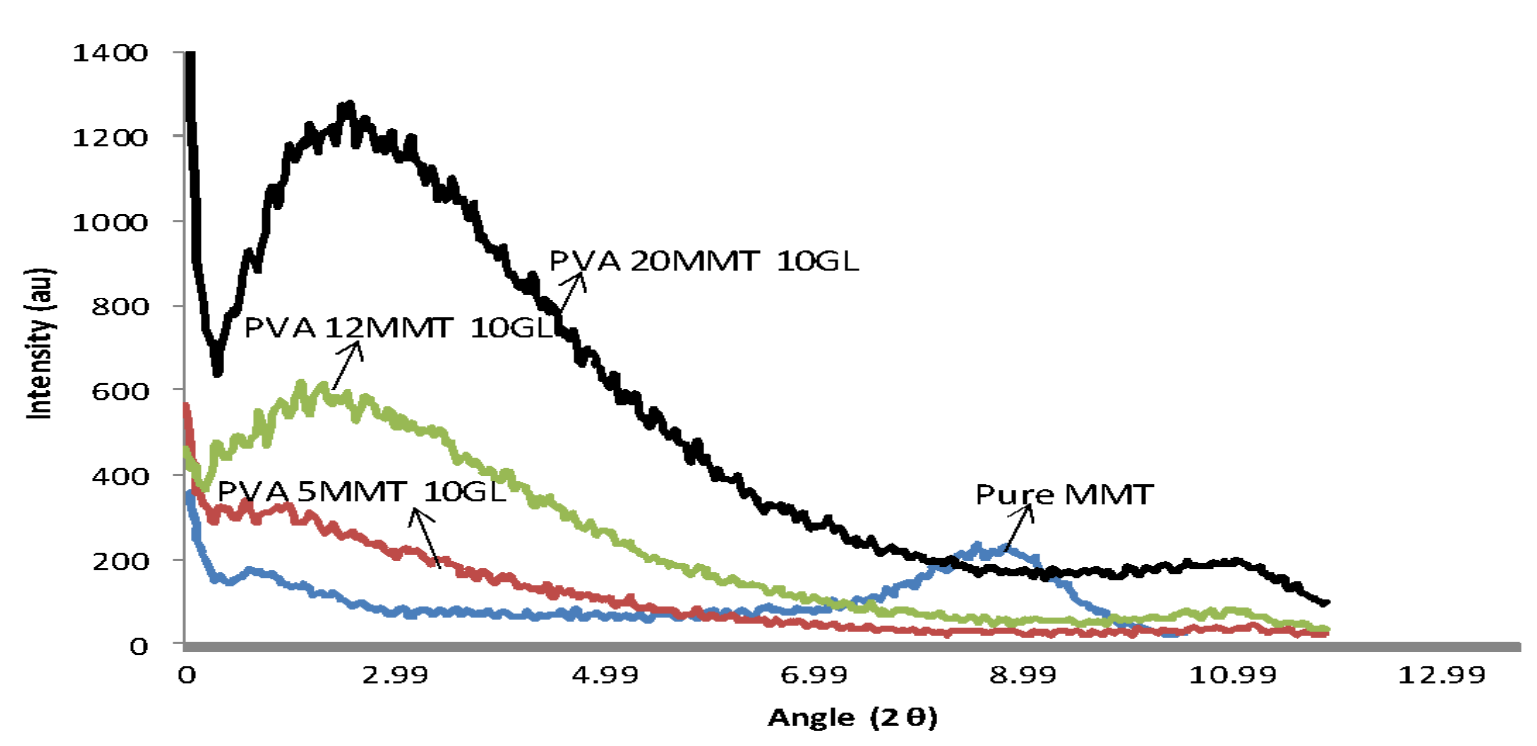

Figure 9. The XRD graphs of PVA-MMT films with different amounts of MMT.

Table 5. The d-space and angles of the XRD peaks of PVA-MMT films

\begin{tabular}{lcccc}
\hline Samples & MMT & PVA 5MMT 10GL & PVA 12MMT 10GL & PVA 20MMT 10GL \\
\hline d-space (nm) & 1.178 & 5.114 & 4.424 & 4.22 \\
Angle (20) & 8.7 & 2 & 2.32 & 2.42 \\
\hline
\end{tabular}

\section{Disc ussion}

MMT characterization: The evaluation of XRD showed a peak at $8.72 \theta$, revealing $1.178 \mathrm{~nm}$ d-space between the silicate layers, which was close to the reported d-space from by the company.

Zetasizer evaluations showed that the zeta potential (ZP), particle size average (PSA), and polydispersity index (PDI) of the MMT suspension $(0.4 \% \mathrm{w} / \mathrm{v})$ were $-30.4,195 \mathrm{~nm}$, and 0.264 , respectively.

As illustrated in Table 2, the PSA of MMT suspension was around $195 \mathrm{~nm}$. Because $97.7 \%$ of the particles had similar size $(260.9 \mathrm{~nm})$, the suspension had high homogeneity. The PSA from Zetasizer was almost 10 times smaller than the value reported by the company, which was probalely due to the soaking, stirring, and sonication treatments in the preparation of MMT (Fig. 1). Therefore, these treatments surely reduced the size of MMT particles. In line with this research, Alshabate et al. (2013) reported that NaMMT suspension had a wide particle size distribution (three peaks), and about $88.2 \%$ of particles had 748.5 $\mathrm{nm}$ sizes, which is actually more than the size of MMT suspension in the present study (3).
PDI is a dimensionless term for demonstrating the band of size distribution, usually ranging from 0.05 to 0.7 , and values higher than 0.7 indicate that the sample is not probably suitable for evaluation by the dynamic light scattering (DLS) technique in Zetasizer. The PDI of the Na-MMT suspension in this study was 0.264 (Table 2), which was suitable and within the range $(3,24)$. $\mathrm{ZP}$ is a term that expresses the potential difference between the medium of suspension and the stationary layer of the fluid, attached to the dispersed particles. ZP of Na-MMT was $-30.4 \mathrm{mV}$, indicating the moderate stability of the nano-particles (25).

Mechanical properties: Increasing the MMT contents caused the improvement of $T S$ and reduced $E \%$. GL caused the improvement of $E \%$, while reducing TS. Figure 3 illustrates these trends.

The presence of $\mathrm{OH}$ groups in GL, smallness of the molecule, and its H-bonds among the polymer chains improved the flexibility and slippage of the polymer chains, leading to a reduction in TS and an increase in $E \%$. Nonetheless, the penetration of polymer chains into the d-space of MMT layers 
reduced the polymer mobility, leading to increase in $T S$, but a reduction in $E \%$.

Mondal et al. (2013) reported the TS and E\% of PVA film with $8 \%$ MMT as $54.95 \mathrm{MPa}$ and $160 \%$, respectively (18), and Lui et al. (2014) reported the $T S$ and $E \%$ of PVA films with $5 \%$ MMT as $53.2 \mathrm{MPa}$ and $111.5 \%$, respectively. In the present study, the TS and $E \%$ of PVA films with 5\% MMT and $0 \%$ GL were obtained as $43.97 \mathrm{MPa}$, and $135.1 \%$, respectively. These results are compatible with the other reported values. Chang et al. (2003) announced the $T S$ and E\% of PVA films (with 8\% MMT) 160 $\mathrm{MPa}$, and 9\%, respectively. The reasons of these differences could be related to the characteristics of PVA, especially polymerization degree, and nanocomposite formulation, which affect the films' mechanical properties extensively.

Water Vapor Permeability (WVP): GL increased $W V P$, while MMT reduced it. It is obvious in Fig. 4 that the slope of increasing the MMT contents at $50 \% \mathrm{GL}$ is much higher when compared to $0 \% \mathrm{GL}$. It reveals the interaction effects of MMT-GL, and proves that different MMT contents did not have any significant effect on $W V P$ at $0 \% \mathrm{GL}$. The reason of insignificancy of MMT on $W V P$ at $0 \% \mathrm{GL}$ is not clear and requires further studies.

The presence of MMT in PVA formulations increases the tortuosity of the diffusive path for water vapor, and provides strong structures between the intercalated silicate layers and the polymer matrix through which the water vapor cannot pass easily. In addition, strong interacting of MMT with polymer matrix limits the motion of polymer chains and creates a more compact film; therefore, the penetration of water vapor through the film will be reduced. Since GL is hydrophilic, it can absorb water vapor and make its diffusion easy. In addition, GL forms many new H-bonds with PVA chains, and as a result, absorption and diffusion of water vapor become faster (26-28).

Mondal et al. (2013) reported that the WVP of PVA films with $8 \%$ MMT (without GL) was $3 \times 10^{-}$ ${ }^{4} \mathrm{~g} / \mathrm{m}$.h, while Liu et al. (2014) reported that the WVP of PVA films with 5\% MMT (without GL) was around $8.5 \times 10^{-5} \mathrm{~g} / \mathrm{m} . \mathrm{h} . \mathrm{kPa}(18,29)$. In the present study, the WVP of PVA films with 5 and 12\%MMT and $0 \% \mathrm{GL}$ was $1 \times 10^{-4}$ and $7 \times 10^{-5} \mathrm{~g} / \mathrm{m} . \mathrm{h} \cdot \mathrm{kPa}$, respectively.
Thickness: The highest thickness of the films $(85 \mu)$ was related to 50\%GL. GL and its H-bonds with PVA could increase the water absorption and moisture content of the films, leading to an increase in the thickness, while MMT could not absorb water and form chemical bonds with PVA as much as GL .

Appearance of PVA-MMT films: The higher slope of MMT reveals that the effect of MMT on $b^{*}$ and $Y I$ was considerably higher when compared to GL, and increased $Y I$ and $b^{*}$ (Fig. 6).

Fig. 6 clearly demonstrates that GL could increase $Y I$ just at 20\%MMT content, while it did not affect $Y I$ at low MMT concentrations. The density and solid contents of the films at 20\%MMT were high, and increasing of the GL contents probably improved the solid contents more, thereby leading to a reduction in transmission, but an increase in YI. At lower MMT contents, increasing of the solids by GL could not affect $Y I$ of the films.

As MMT color is nearly green, the color of PVA films will be changed as a result of the presence of MMT in the films. Theoretically, as the thickness of MMT layers is lower than $1 \mathrm{~nm}$ (lower than the visible light wave number), the transmission of light should be constant, unless MMT layers are not fully spread in the PVA matrix (29).

In the present study, the structure of MMT in PVA was intercalating (the XRD section); thus, opacity rise was expected. MMT layers can be a focus for the scattering light and increasing absorbance of light and opacity, especially if they are not well scattered (11).

Strawhecker and Manias (2000) reported that MMT did not affect the transmission of visible light through PVA films, while the transmission was reduced in the ultraviolet spectrum region (11). Other researchers reported that MMT reduced the transmission of visible light or increased the opacity of PVA films (29).

Fourier transform infrared spectroscopy (FTIR): As can be seen in Fig. 8, by adding 5\%MMT to pure PVA, the intensity of some peaks like $3482(\mathrm{OH}-$ stretching vibration), 3334 (OH-stretching vibration), $1439\left(\mathrm{CH}_{2}\right.$ banding vibration), and $1336 \mathrm{~cm}^{-1}(\mathrm{C}-\mathrm{H}$ angular deformation) increased considerably. In addition, the wave number of these peaks shifted positively revealing the increasing rigidity of the bonds because of the presence of MMT in the polymer. MMT caused the emergence of some new peaks like 3433 (OH-stretching vibration), $3206(\mathrm{OH}-$ 
stretching vibration), 3250 (OH-stretching vibration), 532 (S-S disulfide), and $462 \mathrm{~cm}^{-1}$ (S-S disulfide), while removing other peaks like 3382, 636, 503, and $422 \mathrm{~cm}^{-1}$.

The most important changes in MMT were shifting peaks 1021 and $1054 \mathrm{~cm}^{-1}$ to 1053 and 1126 , respectively. These changes demonstrate the effect of PVA on the Si-O of MMT and its surrounding environment because of the penetration of PVA between the MMT layers (30).

Adding $10 \%$ GL to the film resulted in further changes in the FTIR spectra (Fig. 8). All these changes demonstrate the high compatibility of GL, MMT and PVA with each other. It is noteworthy that the intensity of peaks, related to 5\% MMT-10\% GL film is remarkably lower than the one related to $5 \%$ MMT film, which can prove the plasticizing effect of GL.

X-ray diffraction (XRD): Fig. 9 reveals that the structures of MMT in all the films are intercalated. The d-space between the MMT layers in PVA-MMT with $5 \% \mathrm{MMT}$ is more than $5 \mathrm{~nm}$, and it might have an exfoliate structure, while the films with 12 and 20\%MMT have lower d-space (Table 5).

Fig. 9 illustrates that increasing of the MMT contents can elevate the intensity of related XRD peaks. Increasing of the MMT layers improves the emission of coherent X-rays towards the detector. Table 5 shows the angles and d-space of MMT layers in the films $(11,18,29)$.

\section{Conclusion}

MMT increased the TS, YI, and opacity of PVAMMT films, and reduced the $E \%$ and WVP. The effect of GL on the films was quite opposite the MMT. The interaction effects of MMT-GL on $W V P$, $Y I$ and $b^{*}$ were significant, making the performing of further ANOVA imperative. MMT contents could reduce $W V P$ just at the presence of GL in the films, while GL contents could increase $W V P$ at all MMT concentrations. Furthermore, MMT contents could increase $Y I$ of the films at all GL concentrations, while GL could increase $Y I$ just at 20\%MMT content. Considering the aim of using the film, optimization of MMT and GL in order to obtain desired prosperities is mandatory and critical. The FTIR results proved that both MMT and GL are highly compatible with PVA. The XRD outcome revealed that MMT at low contents can disperse very well in PVA matrix and might attain an exfoliated structure.

\section{Acknowledgement}

This work was carried out under the support of Tarbiate Modares University, Tehran, Iran as part of a $\mathrm{PhD}$ dissertation; so, we gratfully appreciate their kind cooperation. In addition, we sincerely express our gratitude to the technicians of Food and Central Labs in the Faculty of Agriculture, Tarbiate Modares University, Tehran, Iran.

\section{Financial disclosure}

The authors declared no financial interest.

\section{Funding/Support}

This work was financially supported by the Tarbiate Modares University, Tehran, Iran.

\section{References}

1. Alves V, Costa N, Hilliou L, Larotonda F, Gonçalves M, Sereno A, et al. Design of biodegradable composite films for food packaging. Desalination. 2006;199(1-3):331-3.

2. Avella M, De Vlieger JJ, Errico ME, Fischer S, Vacca P, Volpe MG. Biodegradable starch/clay nanocomposite films for food packaging applications. Food Chemistry. 2005;93(3):467-74.

3. Alshabanat M, Al-Arrash A, Mekhamer W. Polystyrene/montmorillonite nanocomposites: study of the morphology and effects of sonication time on thermal stability. J Nanomaterials. 2013;2013:9-.

4. Elbokl TA, Detellier C. Aluminosilicate nanohybrid materials. Intercalation of polystyrene in kaolinite. Journal of Physics and Chemistry of Solids. 2006;67(56):950-5

5. Elbokl TA, Detellier C. Kaolinite-poly(methacrylamide) intercalated nanocomposite via in situ polymerization. Canadian Journal of Chemistry. 2009;87(1 SPEC. ISS.):272-9.

6. Rao Y. Gelatin-clay nanocomposites of improved properties. Polymer. 2007;48(18):5369-75.

7. Martucci JF, Vázquez A, Ruseckaite RA. Nanocomposites based on gelatin and montmorillonite: Morphological and thermal studies. J Therm Anal Calor. 2007;89(1):117-22.

8. Tunç S, Duman O. Preparation and characterization of biodegradable methyl cellulose/montmorillonite nanocomposite films. Applied Clay Science. 2010;48(3):414-24.

9. Theng BKG. The Chemistry of Clay-Organic Reactions. 29 King Street, London, WC2E 8JH: Adam Hilger Ltd., Rank Precision Industries.; 1974. 343pp. p.

10. DeMerlis CC, Schoneker DR. Review of the oral toxicity of polyvinyl alcohol (PVA). Food and Chemical Toxicology. 2003;41(3):319-26. 
11. Strawhecker K, Manias E. Structure and properties of poly (vinyl alcohol)/Na+ montmorillonite nanocomposites. Chemistry of Materials. 2000;12(10):2943-9.

12. Tang X, Alavi S. Recent advances in starch, polyvinyl alcohol based polymer blends, nanocomposites and their biodegradability. Carbohydrate Polymers. 2011;85(1):716.

13. Chang J-H, Jang T-G, Ihn KJ, Lee W-K, Sur GS. Poly (vinyl alcohol) nanocomposites with different clays: Pristine clays and organoclays. Journal of Applied Polymer Science. 2003;90(12):3208-14.

14. Grunlan JC, Grigorian A, Hamilton CB, Mehrabi AR. Effect of clay concentration on the oxygen permeability and optical properties of a modified poly(vinyl alcohol). Journal of Applied Polymer Science. 2004;93(3):1102-9.

15. Mao L, Imam S, Gordon S, Cinelli P, Chiellini E. Extruded cornstarch-glycerol-polyvinyl alcohol blends: Mechanical properties, morphology, and biodegradability. J Polym Environ. 2000;8(4):205-11.

16. Lin CA, Tung CC. The preparation and characterization of glycerol pseudo-thermoplastic starch/glycerol pseudothermoplastic polyvinyl alcohol (GTPS/GTPVA) biodegradable films using the solution casting method. Polym-Plast Technol Eng. 2010;49(3):279-84.

17. ASTM. Standard Test Method for Tensile Properties of Thin Plastic Sheeting. Designation: D882-12. ASTM International, West Conshohocken, PA, www.astm.org 2012.

18. Mondal D, Mollick MMR, Bhowmick B, Maity D, Bain MK, Rana D, et al. Effect of poly(vinyl pyrrolidone) on the morphology and physical properties of poly(vinyl alcohol)/sodium montmorillonite nanocomposite films. Progress in Natural Science: Materials International. 2013;23(6):579-87.

19. Islam MS, Rahaman MS, Yeum JH. Electrospun novel super-absorbent based on polysaccharide-polyvinyl alcohol-montmorillonite clay nanocomposites. Carbohydrate Polymers. 2014;115:69-77.

20. Giménez B, Gómez-Estaca J, Alemán A, Gómez-Guillén MC, Montero MP. Physico-chemical and film forming properties of giant squid (Dosidicus gigas) gelatin. Food Hydrocolloids. 2009;23(3):585-92.

21. Gómez-Estaca J, Montero P, Fernández-Martín F, Alemán A, Gómez-Guillén MC. Physical and chemical properties of tuna-skin and bovine-hide gelatin films with added aqueous oregano and rosemary extracts. Food Hydrocolloids. 2009;23(5):1334-41.

22. ASTM. Standard Test Methods for Water Vapor Transmission of Materials. Designation: E96/E96M-14. ASTM International, West Conshohocken, PA, 2014, www.astm.org2014.

23. ASTM. Standard Practice for Calculating Yellowness and Whiteness Indices from Instrumentally Measured Color Coordinates. Designation: ASTM E313-15. ASTM International, West Conshohocken, PA, www.astm.org 2015.

24. Bohren CF, Huffman DR. Absorption and scattering of light by small particles: John Wiley \& Sons; 2008.

25. Honary S, Zahir F. Effect of zeta potential on the properties of nano-drug delivery systems - A review (Part 1). Trop J Pharm Res. 2013;12(2):255-64.

26. De Azeredo HM. Nanocomposites for food packaging applications. Food Research International. 2009;42(9): 1240-53.

27. Turhan KN, Sahbaz F. Water vapor permeability, tensile properties and solubility of methylcellulose-based edible films. Journal of Food Engineering 2004;61

28. Rhim J-W. Effect of clay contents on mechanical and water vapor barrier properties of agar-based nanocomposite films. Carbohydrate Polymers. 2011;86(2):691-9.

29. Liu G, Song Y, Wang J, Zhuang H, Ma L, Li C, et al. Effects of nanoclay type on the physical and antimicrobial properties of PVOH-based nanocomposite films. LWT - Food Science and Technology. 2014;57(2):562-8.

30. Tzavalas S, Gregoriou VG. Infrared spectroscopy as a tool to monitor the extent of intercalation and exfoliation in polymer clay nanocomposites. Vib Spectrosc. 2009;51(1):39-43. 